\title{
Effect of Periodic Water Clusters on AISI 304 Welded Surfaces
}

\author{
Madhulika Srivastava ${ }^{1}$, Akash Nag ${ }^{2}$, Lucie Krejčí ${ }^{3} \mathbb{D}$, Jana Petrů $^{3} \mathbb{D}$, Somnath Chattopadhyaya ${ }^{2}$ and \\ Sergej Hloch $4,5, *$ (D)
}

1 Department of Mechanical Engineering, Amrita School of Engineering, Amrita Vishwa Vidyapeetham, Chennai 601103, India; s_madhulika@ch.amrita.edu

2 Department of Mechanical Engineering, Indian Institute of Technology (Indian School of Mines), Dhanbad 826004, India; akashnag1992@gmail.com (A.N.); somnathchattopadhyaya@iitism.ac.in (S.C.)

3 Department of Mechanical Engineering, Vysoká Škola Báňská, Technical University, 70800 Ostrava, Czech Republic; lucie.krejci@vsb.cz (L.K.); jana.petru@vsb.cz (J.P.)

4 Faculty of Manufacturing Technologies, Technical University of Kosice, Prešov, Bayerova 1, 08001 Presov, Slovakia

5 Institute of Geonics of the Czech Academy of Sciences, Studentska 1768, 70800 Ostrava-Poruba, Czech Republic

* Correspondence: sergej.hloch@tuke.sk

Citation: Srivastava, M.; Nag, A.;

Krejčí, L.; Petrů, J.; Chattopadhyaya, S.; Hloch, S. Effect of Periodic Water Clusters on AISI 304 Welded Surfaces. Materials 2021, 14, 210. https://doi. org/10.3390/ma14010210

Received: 4 December 2020 Accepted: 31 December 2020 Published: 4 January 2021

Publisher's Note: MDPI stays neutral with regard to jurisdictional clai$\mathrm{ms}$ in published maps and institutional affiliations.

Copyright: (C) 2021 by the authors. Licensee MDPI, Basel, Switzerland. This article is an open access article distributed under the terms and conditions of the Creative Commons Attribution (CC BY) license (https:// creativecommons.org/licenses/by/ $4.0 /)$.
Abstract: This study compared the effect of the interaction time of periodic water clusters on the surface integrity of AISI 304 tungsten inert gas (TIG) welded joints at different excitation frequencies, as the effect of the technological parameters of pulsating water jet (PWJ) on the mechanical properties of TIG welded joints are under-researched. The TIG welded joints were subjected to different frequencies (20 and $40 \mathrm{kHz}$ ) and traverse speeds $(1-4 \mathrm{~mm} / \mathrm{s}$ ) at a water pressure of $40 \mathrm{MPa}$ and a standoff distance of $70 \mathrm{~mm}$. The effect of the interaction of the pulsating jet on the material and the enhancement in its mechanical properties were compared through residual stress measurements, surface roughness, and sub-surface microhardness. A maximum enhancement in the residual stress values of up to $480 \mathrm{MPa}$ was observed in the heat-affected zone, along with a maximum roughness of $6.03 \mu \mathrm{m}$ and a maximum hardness of $551 \mathrm{HV}$ using a frequency of $40 \mathrm{kHz}$. The improvement in the surface characteristics of the welded joints shows the potential of utilizing pulsed water jet technology with an appropriate selection of process parameters in the treatment of welded structures.

Keywords: pulsating water jet; welded joints; stainless steel; residual stress; microhardness; surface roughness

\section{Introduction}

The phenomenon of hydrodynamic erosion has gained increasing attention due to its severe effects on the hydraulic mechanical components such as impellers, valves, fittings, pumps, and hydrofoil surfaces [1,2]. The erosion initiated by impact loading, cyclic loading in the form of a hammer effect, and lateral jetting causes elastic-plastic deformation during the interaction of the jet with the material [3]. Fundamentally, the impact of a water jet or droplet on a solid surface generates stresses that are categorized into two stages. The initial stage is the water hammer effect, which causes compressive stress for a short duration, followed by the shearing action of the material during lateral jetting [4]. The compressive and shear stresses are distributed within the surface and sub-surface layers in the form of shock waves, which are responsible for enhancing the strength and surface integrity of the material. The conclusions inferred from previous experiments suggest that the erosion effect is the consequence of fatigue failure caused by the impact of a jet [5]. The energy of a jet imparted on a solid surface is utilized for treatment applications by exploring the early stages of erosion (incubation). However, at the advanced stages of erosion, disintegration of the material occurs.

In view of the above, the erosion phenomenon (early and advanced stages of erosion) has been investigated using a pulsating (PWJ) or continuous (CWJ) water jet on various 
ductile materials. The water droplet erosion (WDE) mechanism has been investigated on Ti-Al alloys (fully lamellar) [6], during which the test was interrupted at three stages of erosion (i.e., the incubation, maximum erosion, and steady-state stages); the microstructural analysis revealed that the erosion was initiated through inhomogeneous and localized material flow, followed by crack generation on the surface. Moreover, the advanced stages of erosion were directed by the periodic roughening and formation of deep craters. The WDE (early and advanced stages) has also been studied on Ti-6Al-4V surfaces [7], in which the influence of the impact speed on erosion behavior in terms of mass loss was explored. It was observed that at impact speed $(350 \mathrm{~m} / \mathrm{s})$, the maximum erosion rate increases as the initiation time becomes faster. The microstructural analysis revealed that the early erosion was limited to microcracks and isolated pits; however, substantial material removal (subsurface cracking, upheaving) was observed in the advanced stage of erosion. Additionally, the effect of a water jet has also been explored for surface treatment application on various ductile materials, such as aluminum alloys [8], in which the effect of various process parameters (e.g., pressure, number of passes, standoff distance, and feed rate) on the surface roughness and microhardness were investigated. The experimental analysis revealed that an increase in the number of passes (1 to 3), pressure (50-150 MPa), and standoff distance $(20-60 \mathrm{~mm})$ results in higher roughness and hardness values; however, a reverse effect was observed upon increasing the feed rate. Another study [9] investigated the effect of the number of passes, the pressure, and the feed rate on the surface integrity of stainless steel. An enhancement in erosion and roughness was revealed upon increasing the number of passes and the pressure; however, the feed rate showed a reverse effect on the surface erosion and roughness.

Under the action of varying loads (impact and lateral jetting) on the material, modulated water jets are more suitable for material processing in comparison to CWJs [3]. Modulated jets can be generated using different methods, such as self-resonating nozzles, interrupting continuous jets by a rotating disc with an orifice, or using vibrating mechanical devices (e.g., needle or ultrasonic cylinder) inside the pressure chamber. The impact of modulated jets generated using the above methods induces cyclic loading on the material surface [10]. However, the related drawbacks, such as the short life of the moving components and design complexities, are overcome by using ultrasonic generator methods of pulse generation. This technology utilizes a repeated hammer effect produced by the periodic motion of the sonotrode and is advantageous in terms of the lifetime and reliability of the system [10].

The interaction of a PWJ in terms of parametric influence (i.e., pressure, traverse speed, and standoff distance) in the early and advanced stages of erosion [11-14] and the flow field characteristics [15] has been explored previously. Moreover, to eliminate the tensile stresses induced in AISI 304 tungsten inert gas (TIG) welded joints [16], the weld surface has been exposed to a PWJ under variable parametric levels [17]. However, the effect of a variable interaction time and an excitation frequency at the same volumetric flow rate on welded joints has still not been effectively determined. Therefore, in the present study, the effect of different interaction times obtained by varying the nozzle traverse speed $(1-4 \mathrm{~mm} / \mathrm{s})$ with different excitation frequencies $(20,40 \mathrm{kHz})$ on the surface integrity of welded AISI 304 was studied. The surface integrity was studied using residual stress, microhardness, and surface roughness measurements of the sample after PWJ treatment.

The outline of the study is divided into following sections: The introduction is followed by Section 2 (Materials and Methods) which illustrates the sample preparation and the experimental conditions along with the description of the setup used for the experiments and subsequent analysis Section 3 includes the results and the detailed discussion of the results obtained and Section 4 summarizes the primary conclusions of the investigation.

\section{Materials and Methods}

As done previously, double-butt TIG welded joints (Figure 1) of AISI 304 were fabricated at a current of $97 \mathrm{~A}$ with a voltage of $12.1 \mathrm{~V}$ for inner butts and $11.8 \mathrm{~V}$ for outer 
butts [17]. The chemical composition and mechanical properties of AISI 304 are mentioned in Tables 1 and 2 [17]. The joints were then treated using an ultrasonically generated PWJ machine comprising a Hammelmann HDP 253 plunger pump (Hammelmann GmBH, Oelde, Germany) integrated with an ABB robot IRB 6640-180/2.55 (ABB s.r.o, Ostrava, Moravská Ostrava, Czech Republic) for handling the PWJ head and an ECOSON WJUG_630-40 (Ecoson s.r.o, Nové Mesto nad Váhom, Slovakia) sonotrode for the initiation of the PWJ at frequencies of 20 and $40 \mathrm{kHz}$. The system of the PWJ consisted of an acoustic generator with a cylindrical waveguide located inside the acoustic chamber. In this system, the electric signals are transmitted to the liquid inside the chamber in the form of mechanical vibrations from the sonotrode (via the aid of a piezoelectric transducer). These periodic oscillations of the sonotrode cause pressure fluctuations, which are amplified in the mechanical amplifier and guided through the nozzle exit. At the nozzle exit, the pressure fluctuations are converted to velocity fluctuations, causing the breakage of a continuous jet stream into discrete clusters. The repeated impact of these clusters on the material surface induces cyclic stress, which surpasses the ultimate strength of the material and results in elastic-plastic deformation. These deformations are responsible for improving the surface characteristics of the material [4].

Table 1. Composition of AISI 304 [17].

\begin{tabular}{cccccccc}
\hline Element & C (wt.\%) & Mn (wt.\%) & S (wt.\%) & Si (wt.\%) & P (wt.\%) & Ni (wt.\%) & Cr (wt.\%) \\
\hline SS (AISI 304) & 0.08 & 2.00 & 0.03 & 1.0 & 0.04 & $8-10.5$ & $18-20$ \\
\hline
\end{tabular}

Table 2. Mechanical properties of AISI 304 [17].

\begin{tabular}{ccccccc}
\hline STN & Grade & $\begin{array}{c}\text { Tensile } \\
\text { Strength (MPa) }\end{array}$ & $\begin{array}{c}\text { Yield Strength } \\
\mathbf{( M P a )}\end{array}$ & $\begin{array}{c}\text { Elongation } \\
\mathbf{( \% )}\end{array}$ & $\begin{array}{c}\text { Brinell } \\
\text { Hardness }\end{array}$ & Structure \\
\hline 17.240 & 304 & 500 & 210 & 45 & 88 & Austenitic \\
\hline
\end{tabular}

A Stonage nozzle was selected for the treatment under the parameters stated in Table 3. Experiments at a frequency of $f=40 \mathrm{kHz}$ were conducted under the experimental conditions mentioned in Table 1 , after $f=20 \mathrm{kHz}$, which had already been reported earlier [17] (Figure 1). AISI 304 weld zone were exposed to PWJ starting with a traverse speed $v=1 \mathrm{~mm} / \mathrm{s}$ increasing up to $4 \mathrm{~mm} / \mathrm{s}$. This variation in the traverse also varies the number of impingements from 20,000 to 4000 impacts per $\mathrm{mm}$. The same sequence was followed with higher excitation frequency $f=40 \mathrm{kHz}$, as shown in Figure 1. Standoff distance and supply pressure for all experimental runs were kept constant at $z=70 \mathrm{MPa}$ and $p=40 \mathrm{MPa}$.

Table 3. Experimental conditions.

\begin{tabular}{|c|c|c|c|c|c|c|c|c|c|}
\hline S. No. & $f(\mathrm{kHz})$ & $p$ (MPa) & $d(\mathrm{~mm})$ & $z(\mathrm{~mm})$ & $v(\mathrm{~mm} / \mathrm{s})$ & $\begin{array}{c}\text { No. of } \\
\text { Impacts/mm }\end{array}$ & $\begin{array}{c}\text { Impact } \\
\text { Speed } \\
(\mathrm{m} / \mathrm{s})\end{array}$ & $\begin{array}{c}\text { Impact } \\
\text { Pressure } \\
\text { (MPa) }\end{array}$ & $\begin{array}{c}\text { Time Period } \\
\text { of Impact } \\
\text { Pulse ( } \mu s)\end{array}$ \\
\hline 1 & \multirow{4}{*}{20 [17] } & \multirow{8}{*}{40} & \multirow{8}{*}{1.9} & \multirow{8}{*}{70} & 1 & 20,000 & \multirow{8}{*}{254.81} & \multirow{8}{*}{938.47} & \multirow{8}{*}{0.0466} \\
\hline 2 & & & & & 2 & 10,000 & & & \\
\hline 3 & & & & & 3 & 6667 & & & \\
\hline 4 & & & & & 4 & 5000 & & & \\
\hline 5 & \multirow{4}{*}{40} & & & & 1 & 40,000 & & & \\
\hline 6 & & & & & 2 & 20,000 & & & \\
\hline 7 & & & & & 3 & 13,333 & & & \\
\hline 8 & & & & & 4 & 10,000 & & & \\
\hline
\end{tabular}




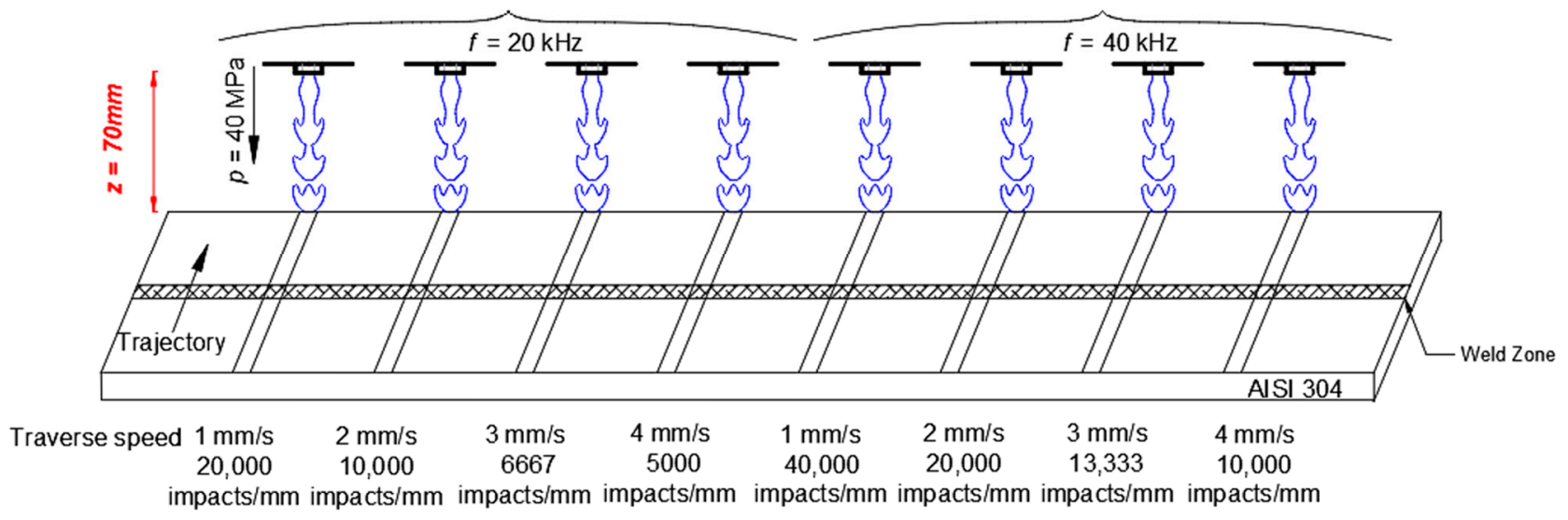

Figure 1. Experimental setup.

Figure $2 \mathrm{a}$ shows the treatment region and welding direction. The treatment was conducted on the surface along the width $(50 \mathrm{~mm})$ of the sample with a consecutive spacing of $5 \mathrm{~mm}$ between the traces to prevent the overlapping of the treated region. For observing the effect of interaction time of the jet with the AISI welded joint surface, a traverse speed of $v=1,2,3$, and $4 \mathrm{~mm} / \mathrm{s}$ was used.

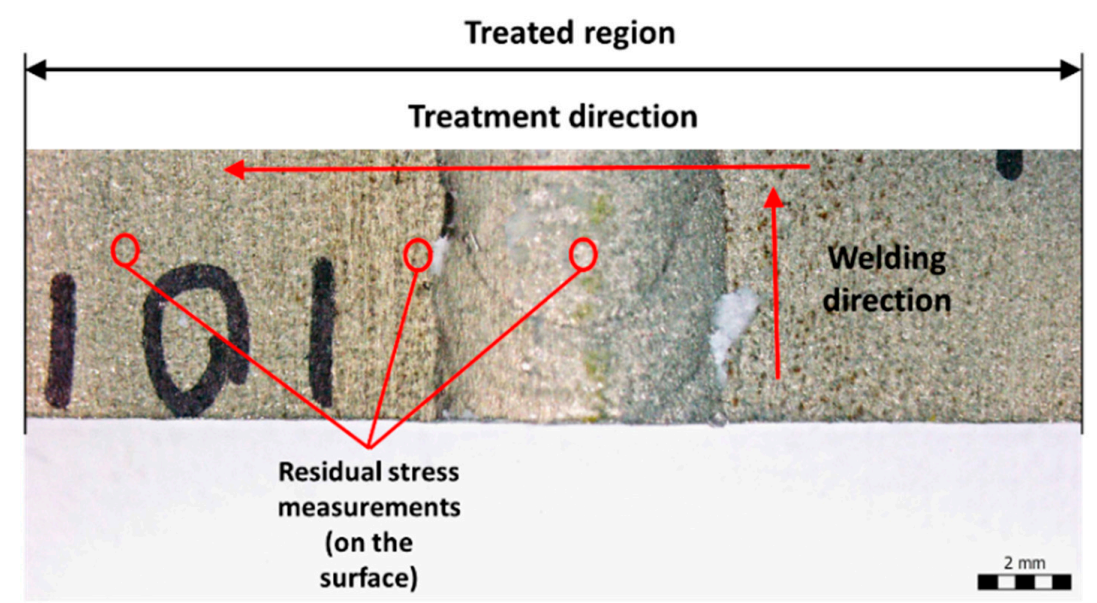

(a)

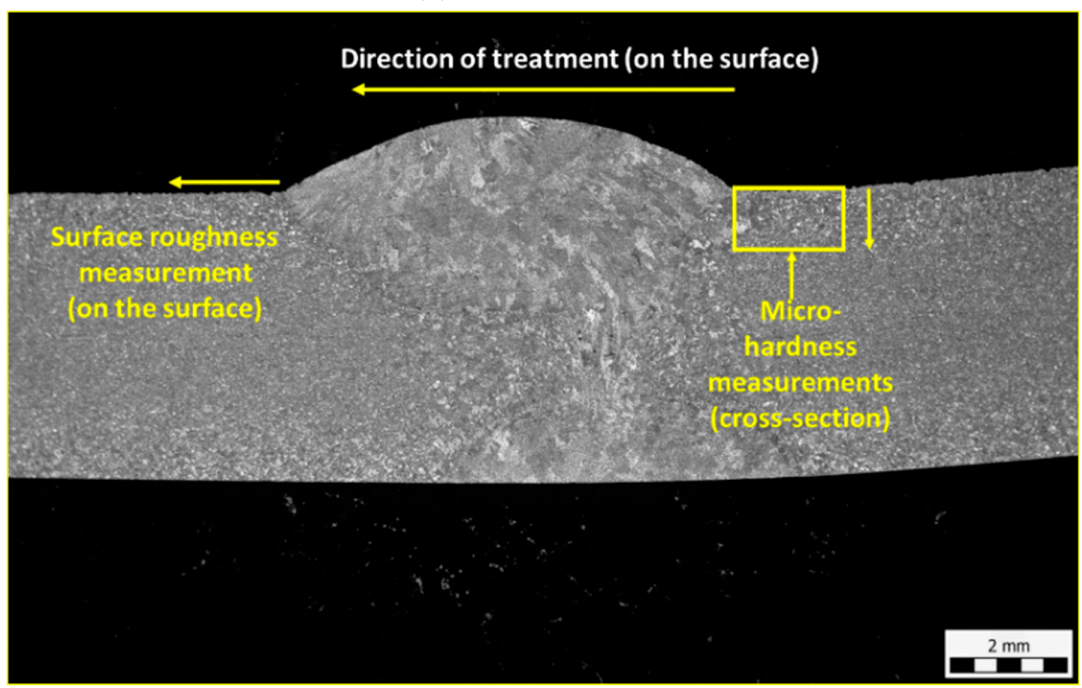

(b)

Figure 2. Optical Microscopy (Macro structure) of (a) the surface of the sample and (b) a cross-section of the sample showing the direction and regions selected for the measurements. 
The surface residual stress (Figure 2a) was measured using X-Ray Diffraction technique (XRD, PROTO Manufacturing Inc., Taylor, MI, USA). The conventional sin $2 \Psi$ method, where the d-spacing is given as a function of $\sin 2 \Psi$ based on an elliptical regression plot, was used to calculate the residual stress (XRD Win 2.0 software). The $\mathrm{Mn}-\mathrm{K} \alpha$ $X$-ray tube of a $2 \mathrm{~mm}$ diameter was used for the measurements. The diffraction shift $\{311\}$ was recorded at each point at rotation angles of $0^{\circ}, 45^{\circ}$, and $90^{\circ}$ with tilt phi angles at $\Psi= \pm 30^{\circ}$. The Bragg's angle was measured as $152.80^{\circ}$. The measurements were conducted on the surface in the three different welded zones (heat affected zone (HAZ), weld, and base) marked in Figure 2a.

The surface roughness of the treated region (Figure $2 b$ ) was quantified using a contact surface roughness tester (Make: Mitutoyo, Kawasaki, Kanagawa, Japan). A stylus of $5 \mu \mathrm{m}$ diameter was traversed with a cutoff length of $l_{c}=0.8 \mathrm{~mm}$. The measured values (repeated five times) are plotted with mean and standard deviation. The roughness was measured only in the HAZ region.

The microhardness measurements were obtained from the sub-surface region of the polished samples (mirror-finished), starting from distance of $20 \mu \mathrm{m}$ from the surface until a $1000 \mu \mathrm{m}$ depth using the Vickers Hardness Tester at a load of $10 \mathrm{gf}$ for a $10 \mathrm{~s}$ indentation time. The direction and the location of the measurements are shown in Figure $2 b$.

The plastic deformation phenomenon in the treated samples was observed using optical microscopy (Figure 2b). Before conducting the optical microscopy, a cross-section of the samples was polished and then etched using Adler reagent.

\section{Results}

\subsection{Surface Residual Stress Measurements}

The residual stress data calculated using XRD measurements are plotted in Figure $3 a, b$ at frequencies of $f=20$ and $40 \mathrm{kHz}$. The deviation of the principal residual stress (maximum) under different treatment conditions at two frequency levels ( $f=20$ and $40 \mathrm{kHz})$ is shown, along with changes in the traverse speed $(v=1-4 \mathrm{~mm} / \mathrm{s})$ in the different zones of the welded joints. A noteworthy change in the residual stress conditions of the material was recorded between the two frequency levels.

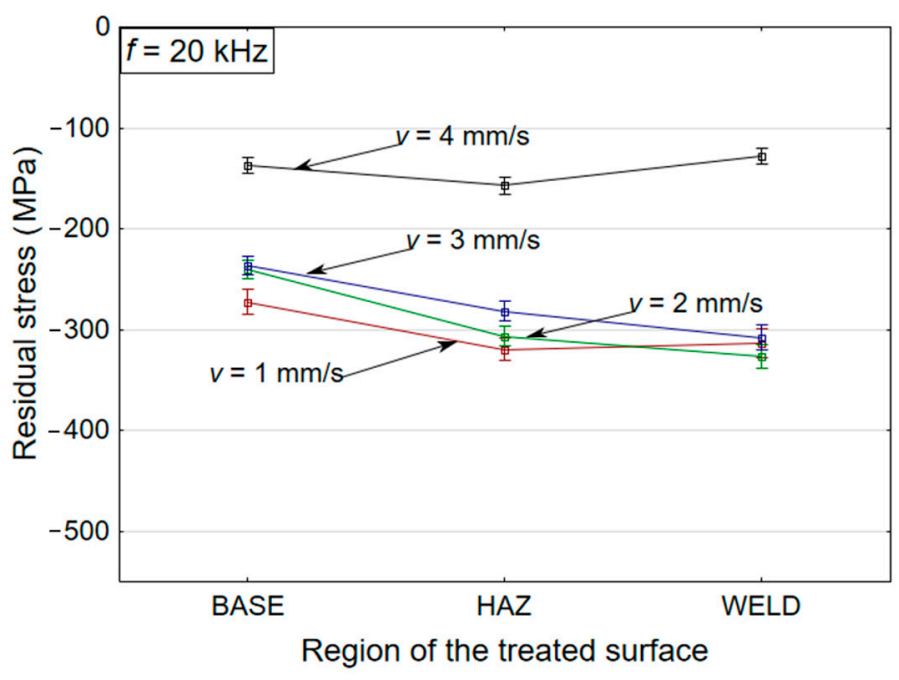

(a)

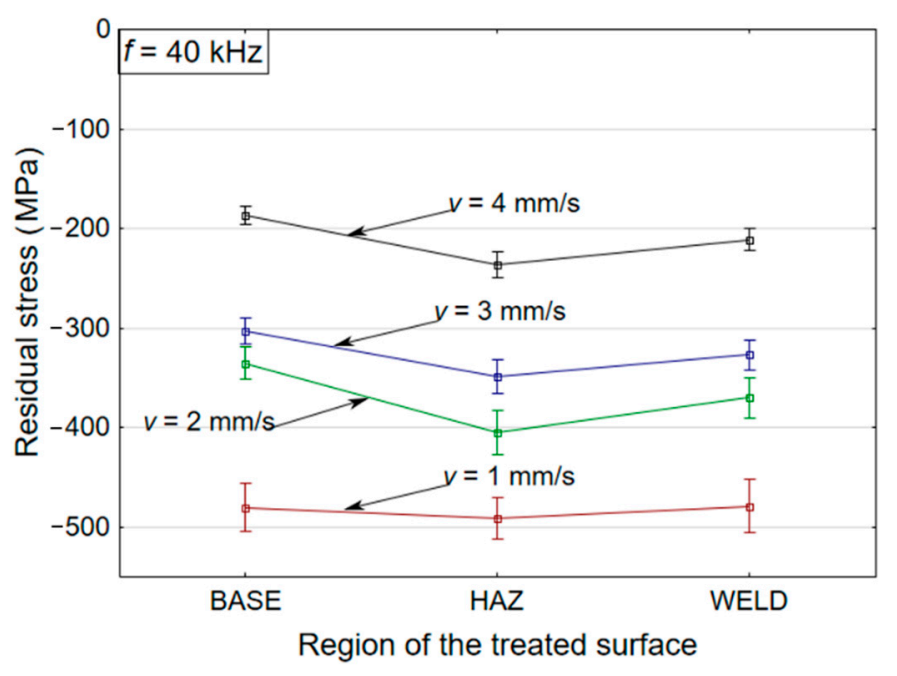

(b)

Figure 3. Variation in the maximum principal residual stress with varying traverse speeds in the different zones of the welded joints at frequencies of (a) $f=20 \mathrm{kHz}$ [17] and (b) $f=40 \mathrm{kHz}$.

At increased frequency levels of $f=40 \mathrm{kHz}$, a higher compressive residual stress of $-480 \mathrm{MPa}$ was recorded at a lower traverse speed $(v=1 \mathrm{~mm} / \mathrm{s})$ in comparison to the lower frequency level of $f=20 \mathrm{kHz}(-272 \mathrm{MPa})$. Differences in the residual stress levels were 
recorded due to the successive increase in the number of impacts, from 20,000 impacts per $\mathrm{mm}$ (at $f=20 \mathrm{kHz}$ ) to 40,000 impacts per $\mathrm{mm}$ (at $f=40 \mathrm{kHz}$ ). This causes a successive increment in the propagation of the compressive and shear stresses (in the form of longitudinal and transverse waves) during the impact and release phases of the shock envelope [18]. The propagation of these different directional waves along the sub-surface of the impacted zone allows dislocations to move and increases in dislocation density [18], which enhances plastic deformation and thus results in an increased magnitude of compressive residual stresses (herein, from $-319 \mathrm{MPa}$ at $f=20 \mathrm{kHz}$ to $-480 \mathrm{MPa}$ at $f=40 \mathrm{kHz}$ ). Primarily, dislocation motion occurs due to crystalline defects in the form of slip bands and twinning, which are responsible for the induction of residual stresses (compressive) during the treatment process [19]. The distribution of the residual stress (compressive) is determined by the parametric conditions.

It is also evident from Figure 3 that with the increase in traverse speed $(v=1-4 \mathrm{~mm} / \mathrm{s})$, the induction of compressive residual stresses decreased (from $-319 \mathrm{MPa}$ to $-157 \mathrm{MPa}$ at $f=20 \mathrm{kHz}$ and from $-479 \mathrm{MPa}$ to $-236 \mathrm{MPa}$ at $f=40 \mathrm{kHz}$ in HAZ) in all the three zones (i.e., weld, HAZ, and base). The reduction in the residual stresses is dependent on the coverage time of the interacting jet, which limits the propagation of compressive and shear stress along the sub-surface layers.

\subsection{Surface Roughness and Microhardness Measurements}

Surface roughness significantly affects the performance of engineering components. It depends on the number of surface impingements that cause localized plastic deformation. The graph shown in Figure 4 depicts the effect of frequency variation $(f=20$ and $40 \mathrm{kHz})$ with an average surface roughness $(R a)$, along with changes in the traverse speed. It was noted that the untreated roughness $(R a)$ of $1.48 \mu \mathrm{m}$ increased to a maximum of $6.08 \mu \mathrm{m}$ at the higher frequency of $40 \mathrm{kHz}$ and at a traverse speed of $v=1 \mathrm{~mm} / \mathrm{s}$. The increased roughness values are attributed to the increase in the number of impacts from 20,000 to 40,000 impacts per $\mathrm{mm}$, which allowed severe plastic deformation at a higher frequency level. Moreover, at the lower traverse speed of $v=1 \mathrm{~mm} / \mathrm{s}$, higher roughness values were recorded $(R a=4.26 \mu \mathrm{m}$ at $f=20 \mathrm{kHz}$ and $R a=6.083 \mu \mathrm{m}$ at $f=40 \mathrm{kHz})$ in comparison to the higher traverse speed of $v=4 \mathrm{~mm} / \mathrm{s}$. This is due to the contact time of the interacting jet, which determines the duration of shock wave propagation beneath the treated region.

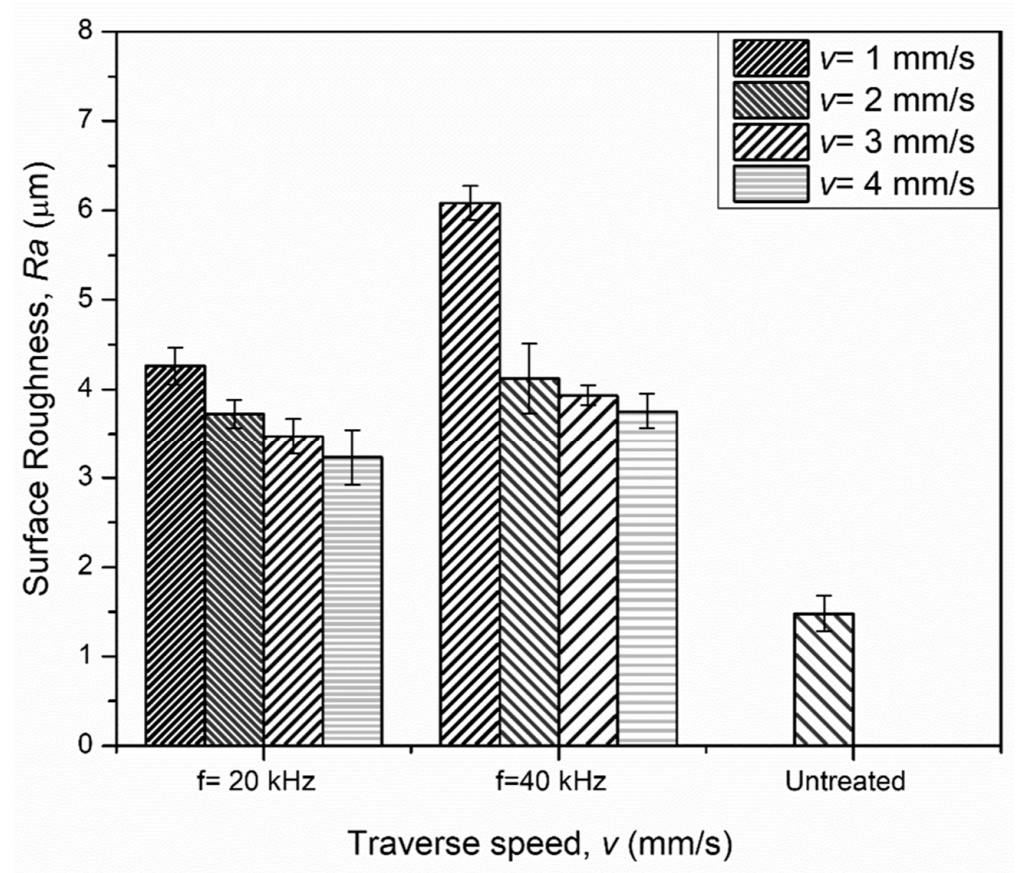

Figure 4. Variation in surface roughness at frequencies of $f=20 \mathrm{kHz}$ [17] and $f=40 \mathrm{kHz}$ at different traverse speeds. 
The cross-sectional analysis of the treated region revealed the effect of the treatment process on the strength of the material as a result of non-uniform plastic deformation [20]. Generally, plastic deformation in metals involves the motion of dislocations. These dislocations are more prominent on the surface areas adjacent to the impacted surface. During plastic deformation, these dislocations in the impacted region are obstructed by the motion of adjacent dislocations, thus causing hardening or strengthening of the material [9].

The measurements were carried out in each sample along the depth (from 20 to $1000 \mu \mathrm{m})$. The hardness values are plotted in the graph in Figure 5 with depth variation for the untreated and treated samples (in HAZ) at $p=40 \mathrm{MPa}$ and $f=20$ or $40 \mathrm{kHz}$ in Figure $5 a, b$, respectively. A substantial increase in hardness was observed near the treated region in all samples, in contrast to the results of the untreated sample. The untreated sample showed a microhardness value of $318 \mathrm{HV}$, which was enhanced up to $551 \mathrm{HV}$ after the treatment. It is evident from Figure 4 that the maximum increase in the hardness of the treated surface was obtained up to a depth of $\sim 100 \mu \mathrm{m}$ at both frequency levels $(f=20$ and $40 \mathrm{kHz}$ ). At the higher frequency level of $f=40 \mathrm{kHz}$, higher hardness values (up to $551 \mathrm{HV}$ ) were measured owing to the enhanced number of impacts (from 20,000 to 40,000 impacts per $\mathrm{mm}$ at $v=1 \mathrm{~mm} / \mathrm{s})$. The increase in the number of impacts (40,000 impacts per $\mathrm{mm}$ ) allowed for the enhanced propagation of compressive stress and strengthening of the layer beneath the impacted surface through the motion of dislocations. These results also agree with the residual stress values measured on the surface of the HAZ. It is also noted that, at the lower traverse speed of $v=1 \mathrm{~mm} / \mathrm{s}$, higher hardness values $(551 \mathrm{HV})$ were recorded, due to the difference in the duration for which the interacting jet was incident on the sample surface, which induced higher values of residual stress and microhardness.

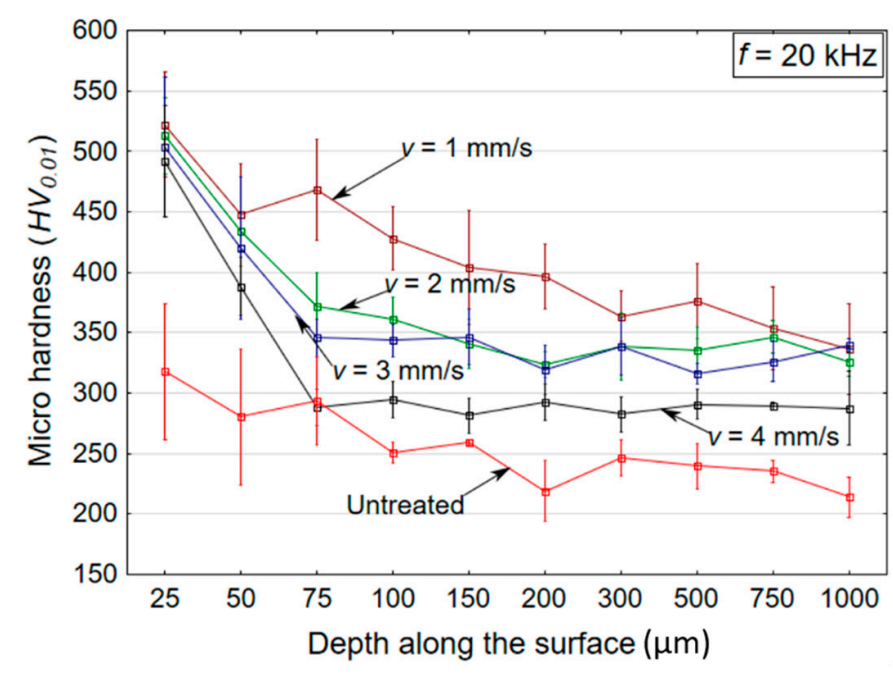

(a)

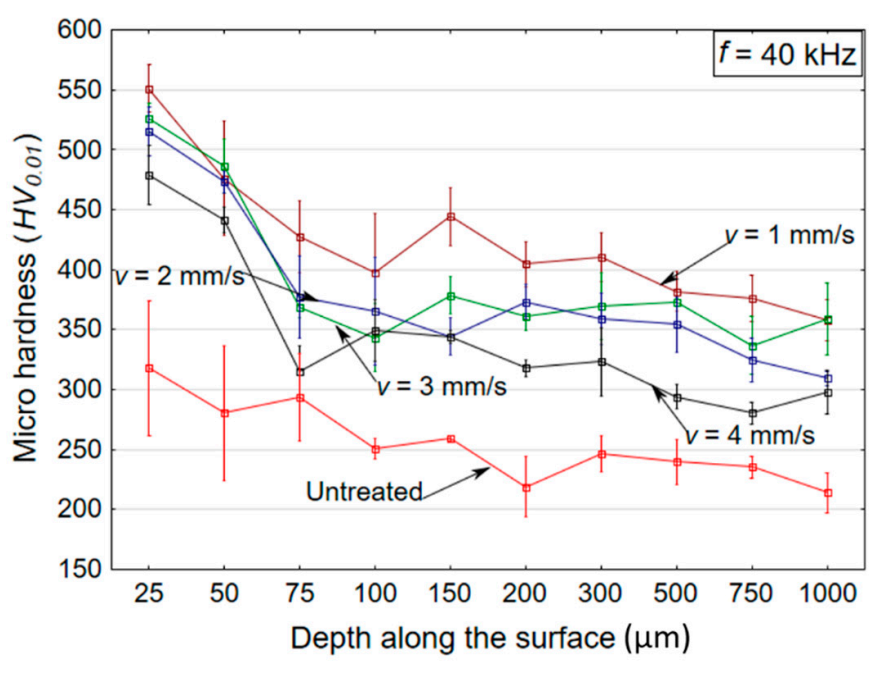

(b)

Figure 5. Variation in the microhardness along the depth at (a) $f=20 \mathrm{kHz}$ and (b) $f=40 \mathrm{kHz}$.

\subsection{Optical Microscopy}

The polished samples after etching were subjected to an optical microscopy examination to elucidate the effect of plastic deformation along the cross-section of the samples. Figures 6 and 7 illustrate the state of plastic deformation caused under the variation in the number of impacts (or frequency change from $f=20$ to $40 \mathrm{kHz}$ ). At $f=40 \mathrm{kHz}$, deformation was observed in the form of craters and deformed grains. These features are the outcome of the repeated impact of the clusters of the PWJ (maximum $6667(20 \mathrm{kHz})-13,334$ impacts per $\mathrm{mm}$ at $v=3 \mathrm{~mm} / \mathrm{s}$ ). The impact of the jet on the materials caused stress distribution and shock wave propagation. On striking the surface asperities, higher impact pressures were generated and the energy accumulated in the weaker sections (grain boundaries and pits) of the material. The repeated impact prompted failure due to the interaction between 
the impact and the reflected waves, and resulted in the formation of cracks, craters, and deformed grains. The lateral jetting after the initial impact phase was responsible for the formation of craters (Figure $6 \mathrm{~b}$ ). Moreover, throughout the propagation of the stress waves within the material, dislocations moved and were occasionally hindered due to the presence of other dislocations in the lattice. The hindrance between the dislocations was responsible for the strengthening of the material [21]. Dislocations in the form of slip lines are evident in Figure 6d.
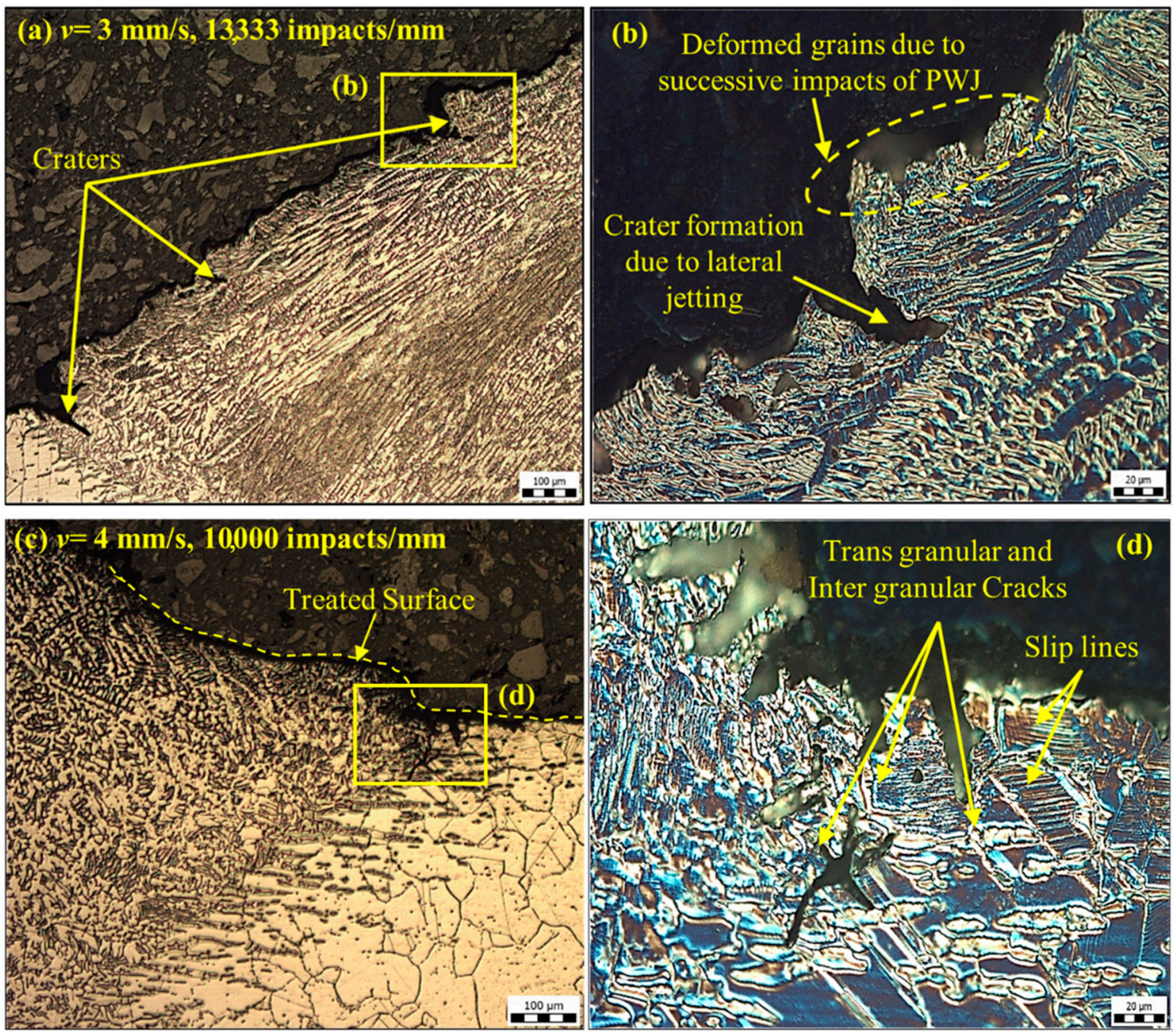

Figure 6. Optical microscopy of a cross-section of the samples treated by pulsating water jet (PWJ) at $f=40 \mathrm{kHz}(\mathrm{a})$ at $v=3 \mathrm{~mm} / \mathrm{s}(100 \mu \mathrm{m})$, with $(\mathbf{b})$ a magnified view at $20 \mu \mathrm{m}$, and (c) at $v=4 \mathrm{~mm} / \mathrm{s}(100 \mu \mathrm{m})$, with a (d) magnified view at $20 \mu \mathrm{m}$.

At $f=20 \mathrm{kHz}$, the presence of impact craters along with sub-surface deformities and slip lines with no splintering of grains is clearly evident in Figure 7. On comparing the intensity of the deformation, due to the increase in the number of impacts from $\sim 6667$ to 13,334 impacts per $\mathrm{mm}$ (at $v=3 \mathrm{~mm} / \mathrm{s}$ ) at the higher frequency $f=40 \mathrm{kHz}$, severe sub-surface deformation features such as intergranular and transgranular crack formation were observed, along with the presence of slip lines. These features were observed due to the enhanced compressive stress and shear stress propagation along the highly stressed regions when a larger number of impacts were incident on the surface. 

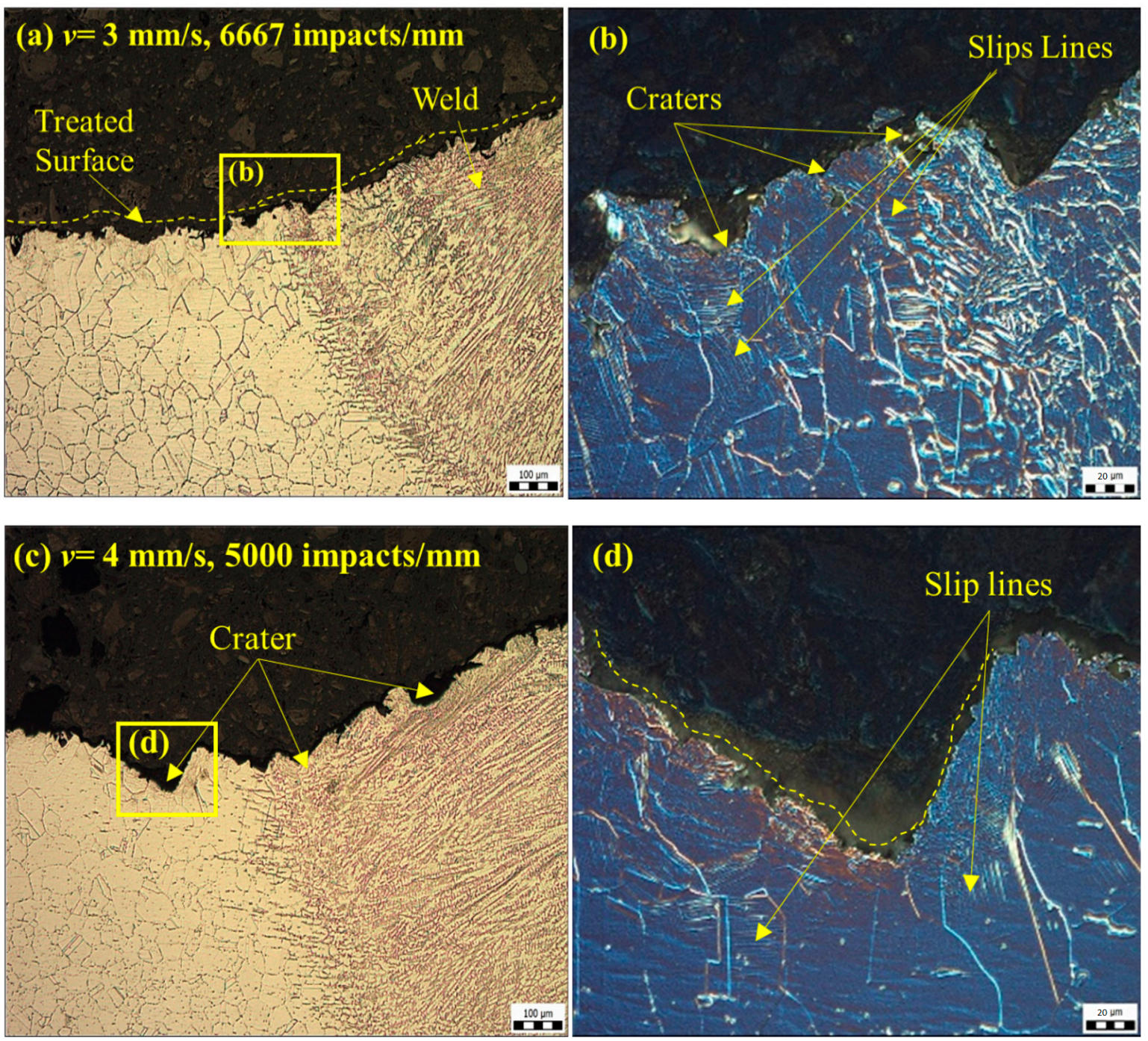

Figure 7. Optical microscopy of a cross-section of the samples treated by PWJ at $f=20 \mathrm{kHz}(\mathbf{a})$ at $v=3 \mathrm{~mm} / \mathrm{s}(100 \mu \mathrm{m})$, with (b) a magnified view at $20 \mu \mathrm{m}$, and (c) at $v=4 \mathrm{~mm} / \mathrm{s}(100 \mu \mathrm{m})$, with a (d) magnified view at $20 \mu \mathrm{m}$. [17].

Figure 8 shows the grains observed through optical microscopy along the cross-section of a sample in the HAZ. The grain size was measured in the treatment direction and the grain size was plotted as a function of the frequency (Figure 9). Samples treated at different frequencies $(0,20$, and $40 \mathrm{kHz})$ with a constant traverse speed of $v=4 \mathrm{~mm} / \mathrm{s}$ were used for this evaluation.

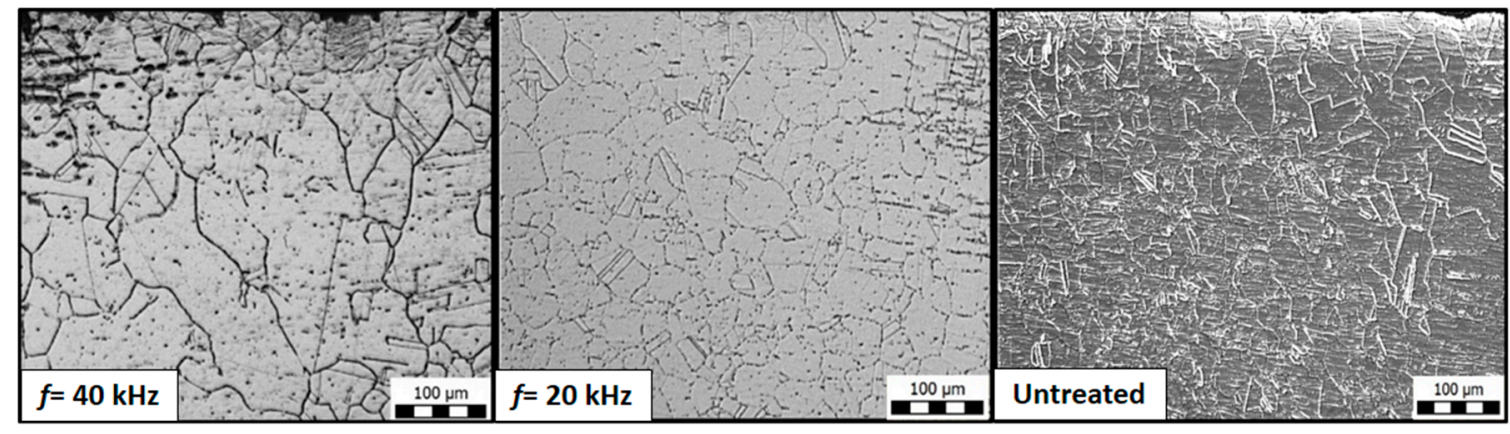

Figure 8. Optical microscopy of a cross-section of the samples in the HAZ at $100 \mu \mathrm{m}$. 


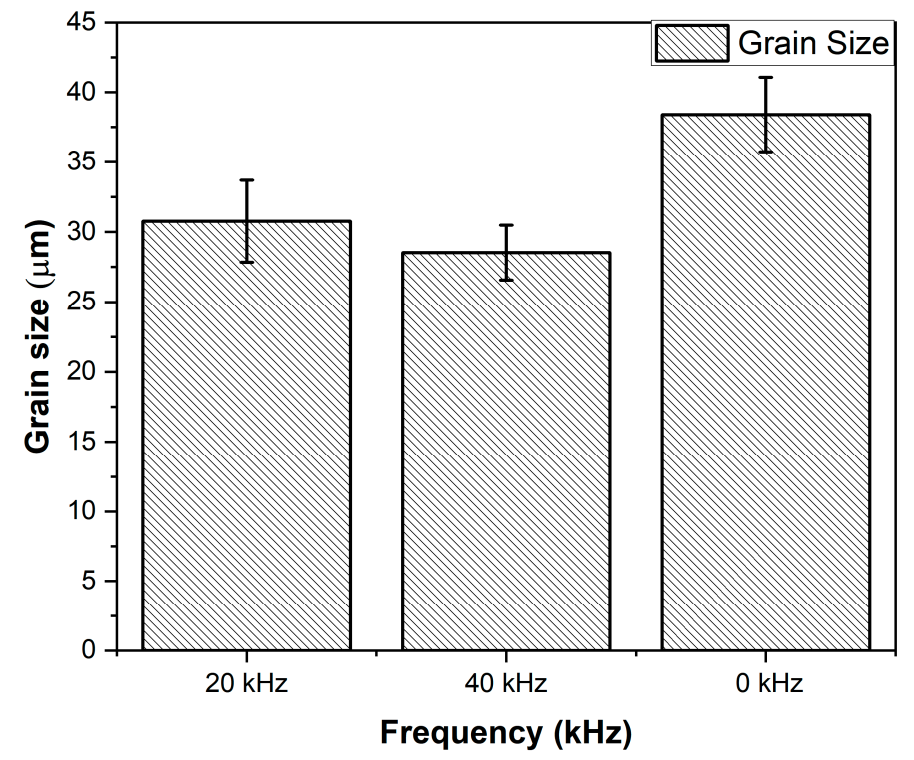

Figure 9. Grain size as a function of frequency.

It is evident from Figure 9 that upon increasing the frequency from 0 to $40 \mathrm{kHz}$, finer grains were observed. The original grain (untreated or $0 \mathrm{kHz}$ ) of $38.40 \mu \mathrm{m}$ was refined to $28.53 \mu \mathrm{m}$ (minimum) at a frequency of $40 \mathrm{kHz}$. This effect is attributed to the phenomenon of grain boundary reforming [21]. The repeated hammering effect by the clusters of the jet caused plastic deformation in the sub-surface regions due to the propagation of the directional waves within the material. This propagation initiated the motion of dislocations and allowed them to rearrange and form new sub-boundaries. The successive impacts of the clusters increased the density of the dislocations and promoted the reformation of the grain boundaries. At the increased frequency level of $f=40 \mathrm{kHz}$, as the number of impacts increased (from 5000 impacts per mm at $f=20 \mathrm{kHz}$ to 10,000 impacts per mm at $f=40 \mathrm{kHz}$ for $v=4 \mathrm{~mm} / \mathrm{s}$ ), a greater hammering effect occurred on the surface, leading to grain refinement, resulting in smaller grain sizes $(28.53 \mu \mathrm{m})$ than those obtained at $f=20 \mathrm{kHz}$ $(30.77 \mu \mathrm{m})$.

\section{Conclusions}

This study compared the effect of the excitation frequency on the surface integrity of AISI 304 TIG welded joints at varying nozzle traverse speeds. The effects were compared through residual stress, surface roughness, microhardness measurements, and optical analysis of the weldment. The obtained results can be summarized as follows:

The residual stress measurements showed that the initial condition of $-122 \mathrm{MPa}$ in HAZ improved to a maximum of $-480 \mathrm{MPa}$ at $f=40 \mathrm{kHz}$ and of $-319 \mathrm{MPa}$ at $f=20 \mathrm{kHz}$ at a lower traverse speed $(v=1 \mathrm{~mm} / \mathrm{s}$ ). It was also observed that the residual stress (compressive) distribution could be determined through the process parameters and material characteristics.

The surface roughness $(R a)$ value recorded in the untreated sample was $1.48 \mu \mathrm{m}$, which was increased to a maximum of $6.08 \mu \mathrm{m}$ at the higher frequency of $f=40 \mathrm{kHz}$ at $v=1 \mathrm{~mm} / \mathrm{s}$. This was attributed to the coverage time of the interacting jet.

The initial microhardness of the untreated welded joints was $318 \mathrm{HV}$, which increased to a maximum of $551 \mathrm{HV}$ at $f=40 \mathrm{kHz}$. Moreover, the maximum increase in microhardness was observed at a lower traverse speed $(v=1 \mathrm{~mm} / \mathrm{s})$. A significant increase in hardening up to a depth of $100 \mu \mathrm{m}$ was obtained at both frequency levels $(f=20$ and $40 \mathrm{kHz})$.

The optical microscopy showed the presence of surface features such as slip bands and twin boundaries predominantly in the sub-surface region in comparison to the untreated samples. This indicates the intensity of the deformation under various experimental 
conditions. Additionally, the initial grain size of $38.40 \mu \mathrm{m}$ was refined by $19.86 \%$ (30.77 $\mu \mathrm{m})$ at $f=20 \mathrm{kHz}$ and by $25.7 \%(28.53 \mu \mathrm{m})$ at $f=40 \mathrm{kHz}$.

The present study revealed the effect of the technological parameters, excitation frequency, and traverse speed of PWJ on TIG welded stainless steel surface. The enhancement in the mechanical properties shows the probability of utilizing the technology for the surface treatment application as it will be helpful in determining the appropriate parameters. However, for the surface treatment application the effect of variation of parameters should be explored in detail to ensure the surface integrity of the treated surface.

Author Contributions: Conceptualization, M.S. and S.H.; methodology, M.S. and S.H.; software, L.K.; validation, M.S. and A.N.; formal analysis, M.S.; investigation, M.S. and A.N.; resources, L.K. and J.P.; data curation, L.K., J.P. and S.H.; writing—original draft preparation, M.S. and A.N.; writing—review and editing, S.H., S.C., and A.N.; supervision, S.H. and S.C.; project administration, S.H.; funding acquisition, S.H. All authors have read and agreed to the published version of the manuscript.

Funding: This work was supported by the Slovak Research and Development Agency under contract no. APVV-17-0490 and the Scientific Grant Agency VEGA 1/0096/18, and was a joint collaboration between the Indian Institute of Technology (Indian School of Mines), Dhanbad, India and the Institute of Geonics, Ostrava, Czech Republic. The experiments were carried out at the Institute of Geonics with the support of the Institute of Clean Technologies for Mining and Utilization of Raw Materials for Energy Use-Sustainability Program, reg. no. LO1406 financed by the Ministry of Education, Youth, and Sports of the Czech Republic, as well as with the support for long-term conceptual development from the research institution RVO: 68145535.

Institutional Review Board Statement: Not applicable.

Informed Consent Statement: Not applicable.

Data Availability Statement: The data presented in this study are available on request from the corresponding author.

Acknowledgments: The authors thank Jiri Klich for his contribution and help in performing the experiments. The residual stress measurements were carried out with cooperation from the Directorate of Advanced Material and Processes, Materials Development Division, Defense Research and Development Laboratory, Hyderabad, India.

Conflicts of Interest: The authors declare no conflict of interest. The funders had no role in the design of the study; in the collection, analyses, or interpretation of data; in the writing of the manuscript, or in the decision to publish the results.

\section{References}

1. Ju, D.; Han, B. Investigation of water cavitation peening-induced microstructures in the near-surface layer of pure titanium. $J$. Mater. Process. Technol. 2009, 209, 4789-4794. [CrossRef]

2. Marín, J.F.S.; Blanco, J.; Giraldo, J.; Toro, A. Cavitation erosion of martensitic and austenitic stainless steel welded coatings. Wear 2011, 271, 1445-1453. [CrossRef]

3. Wang, Z.; Kang, Y.; Wang, X.; Li, D.; Shi, H. Effects of modulation position on the impact performance of mechanically modulated pulsed water jet. J. Manuf. Process. 2020, 56, 510-521. [CrossRef]

4. Foldyna, J. Use of Acoustic Waves for Pulsating Water Jet Generation. In Acoustic Waves_From Microdevices to Helioseismology; IntechOpen: London, UK, 2011; pp. 323-342. [CrossRef]

5. Richman, R.H.; Mcnaughton, W.P. Correlation of cavitation properties of metals erosion behavior with mechanical. Wear 1990, 140, 63-82. [CrossRef]

6. Mahdipoor, M.; Kevorkov, D.; Jedrzejowski, P.; Medraj, M. Water droplet erosion mechanism of nearly fully-lamellar gamma TiAl alloy. Mater. Des. 2016, 89, 1095-1106. [CrossRef]

7. Gujba, A.; Hackel, L.; Kevorkov, D.; Medraj, M. Water droplet erosion behaviour of Ti-6Al-4V and mechanisms of material damage at the early and advanced stages. Wear 2016, 109-122. [CrossRef]

8. Azhari, A.; Schindler, C.; Li, B. Effect of waterjet peening on aluminum alloy 5005. Int. J. Adv. Manuf. Technol. 2013, 67, 785-795. [CrossRef]

9. Azhari, A.; Schindler, C.; Kerscher, E.; Grad, P. Improving surface hardness of austenitic stainless steel using waterjet peening process. Int. J. Adv. Manuf. Technol. 2012, 63, 1035-1046. [CrossRef]

10. Zeleňák, M.; Ř́ha, Z.; Jandačka, P. Visualization and velocity analysis of a high-speed modulated water jet generated by a hydrodynamic nozzle. Measurement 2020, 159, 107753. [CrossRef] 
11. Hloch, S.; Adamčík, P.; Nag, A.; Srivastava, M.; Čuha, D.; Müller, M.; Hromasová, M.; Klich, J. Hydrodynamic ductile erosion of aluminium by a pulsed water jet moving in an inclined trajectory. Wear 2019, 178-192. [CrossRef]

12. Hloch, S.; Srivastava, M.; Nag, A.; Müller, M.; Hromasová, M.; Svobodová, J.; Kruml, T.; Chlupová, A. Effect of pressure of pulsating water jet moving along stair trajectory on erosion depth, surface morphology and microhardness. Wear 2020, 203278. [CrossRef]

13. Foldyna, J.; Klich, J.; Hlavacek, P.; Zelenak, M.; Scucka, J. Erosion of Metals by Pulsating Water. Jet. Teh. Vjesn. Gaz. 2012, 19, 381-386.

14. Foldyna, J.; Sitek, L.; Ščučka, J.; Martinec, P.; Valíček, J.; Páleníková, K. Effects of pulsating water jet impact on aluminium surface. J. Mater. Process. Technol. 2009, 209, 6174-6180. [CrossRef]

15. Zelenak, M.; Foldyna, J.; Scucka, J.; Hloch, S.; Riha, Z. Visualisation and measurement of high-speed pulsating and continuous water jets. Measurement 2015, 72, 1-8. [CrossRef]

16. Abdullah, A.; Malaki, M.; Eskandari, A. Strength enhancement of the welded structures by ultrasonic peening. Mater. Des. 2012, 38, 7-18. [CrossRef]

17. Srivastava, M.; Hloch, S.; Krejci, L.; Chattopadhyaya, S.; Dixit, A.R.; Foldyna, J. Residual stress and surface properties of stainless steel welded joints induced by ultrasonic pulsed water jet peening. Measurement 2018, 127, 453-462. [CrossRef]

18. Mahdipoor, M.S. Water Droplet Erosion Resistant Materials and Surface Treatments. Ph.D. Thesis, Concordia University, Montreal, QC, Canada, 2016.

19. Callister, W.D.; Rethwisch, D.G. Materials Science and Engineering: An Introduction; Wiley: Hoboken, NJ, USA, 2010; Volume 1, ISBN 9788578110796.

20. Azhari, A.; Sulaiman, S.; Rao, A.K.P. A review on the application of peening processes for surface treatment. IOP Conf. Series: Mater. Sci. Eng. 2016, 114, 012002. [CrossRef]

21. Yin, D.; Wang, D.; Jing, H.; Huo, L. The effects of ultrasonic peening treatment on the ultra-long life fatigue behavior of welded joints. Mater. Des. 2010, 31, 3299-3307. [CrossRef] 